rates, payer mix, and costs. Crit Care Med 2010;38(1):65-71.

34. Halpern NA. Can the costs of critical care be controlled? Curr Opin Crit Care 2009; 15(6):591-596.

35. Boyko Y, Ording H, Jennum P. Sleep disturbances in critically ill patients in ICU: how much do we know? Acta Anaesthesiol Scand 2012;56(8):950-958.

36. Roche-Campo F, Thille AW, Drouot X, Galia F, Margarit L, Cordoba-Izquierdo A, et al. Comparison of sleep quality with mechanical versus spontaneous ventilation during weaning of critically ill tracheostomized patients. Crit Care Med 2013;41(7): 1637-1644.

37. Cabello B, Thille AW, Drouot X, Galia F, Mancebo J, d'Ortho M-P, et al. Sleep quality in mechanically ventilated patients: comparison of three ventilatory modes. Crit Care Med 2008;36(6):1749-1755.

38. Alexopoulou C, Kondili E, Plataki M, Georgopoulos D. Patient-ventilator synchrony and sleep quality with proportional assist and pressure support ventilation. Intensive Care Med 2013;39(6):1040-1047.

39. Bosma K, Ferreyra G, Ambrogio C, Pasero D, Mirabella L, Braghiroli A, et al. Patientventilator interaction and sleep in mechanically ventilated patients: pressure support versus proportional assist ventilation. Crit Care Med 2007;35(4):1048-1054.

40. Delisle S, Ouellet P, Bellemare P, Tetrault J-P, Arsenault P. Sleep quality in mechanically ventilated patients: comparison between NAVA and PSV modes. Ann Intensive Care 2011;1(42):1-8.

41. Fanfulla F, Delmastro M, Berardinelli A, Lupo NDA, Nava S. Effects of different ventilator settings on sleep and inspiratory effort in patients with neuromuscular disease. Am J Respir Crit Care Med 2005; 172(5):619-624.

42. Parthasarathy S, Tobin MJ. Effect of ventilator mode on sleep quality in critically ill patients. Am J Respir Crit Care Med 2002; 166(11):1423-1429.

43. Vincent J-L. We should abandon randomized controlled trials in the intensive care unit. Crit Care Med 2010;38(10):S534S538.

44. Nava S, Bruschi C, Fracchia C, Braschi A, Rubini F. Patient-ventilator interaction and inspiratory effort during pressure support ventilation in patients with differrent pathologies. Eur Respir J 1997; 10(1):177-183.

DOI: $10.4187 /$ respcare.02818

\section{The Whisper Game}

\section{To the Editor:}

There is an interesting game called "telephone" or "whispers," in which a message is passed on, in a whisper, down a line of people, and then the last person speaks the message out loud. The final version of the message is usually radically changed from the original. Reference to this game is sometimes used to call attention to distorted information in research papers.

In the July issue of ResPiRATORy CARE, Mark Siobal and colleagues presented an elaborate and well conducted study comparing ventilatory volumetric capnography to other methods. ${ }^{1}$ While I am reluctant to criticize such a good paper, some minor mathematical errors crept in that reminded me of the whisper game.

In the Discussion section, on page 1149, the important equation relating the partial pressure of $\mathrm{CO}_{2}$ in arterial blood, $\mathrm{CO}_{2}$ production, and minute alveolar ventilation is presented as:

$$
\mathrm{P}_{\mathrm{aCO}_{2}}=\dot{\mathrm{V}}_{\mathrm{CO}_{2}} / \dot{\mathrm{V}}_{\mathrm{A}}
$$

A simple dimensional analysis shows that this equation is wrong (a whisper error?) The left hand side of the equation has units of pressure, but the right hand side of the equation is dimensionless (ie, units of flow in the numerator cancel units of flow in the denominator). The correct version of this equation is:

$$
\mathrm{P}_{\mathrm{aCO}_{2}} \propto \dot{\mathrm{V}}_{\mathrm{CO}_{2}} / \dot{\mathrm{V}}_{\mathrm{A}}
$$

where the symbol, $\propto$ means "is proportional to." In Siobal's paper ${ }^{1}$ the equation also appears in Figure 7 (same page), and they reference a paper by Tusman et al, ${ }^{2}$ who give a simplified version of the equation:

$$
\mathrm{P}_{\mathrm{aCO}_{2}}=\left(\mathrm{K} \times \mathrm{V}_{\mathrm{CO}_{2}}\right) / \dot{\mathrm{V}}_{\mathrm{A}}
$$

where $\mathrm{K}$ is called "a constant" without further explanation. (Note that the above equation from the paper has a typo: it is missing the dot over the $\mathrm{V}$ in the numerator. The dot is a mathematical symbol denoting the derivative, in this case meaning the change in volume with respect to time: ie, flow).

The traditional and more useful form of the equation is:

$$
\mathrm{P}_{\mathrm{aCO}_{2}}=\left(0.863 \times \dot{\mathrm{V}}_{\mathrm{CO}_{2}}\right) / \dot{\mathrm{V}}_{\mathrm{A}}
$$

where $\mathrm{P}_{\mathrm{aCO}_{2}}=$ arterial carbon dioxide tension ( $\mathrm{mm} \mathrm{Hg}$ ), $\dot{\mathrm{V}}_{\mathrm{CO}_{2}}=$ carbon dioxide production $(\mathrm{mL} / \mathrm{min})$, and $\dot{\mathrm{V}}_{\mathrm{A}}=$ alveolar ventilation $(\mathrm{L} / \mathrm{min})$.
The factor 0.863 converts concentration to partial pressure and also corrects for the fact that $\mathrm{CO}_{2}$ production is usually expressed at standard temperature and pressure dry (STPD), whereas alveolar ventilation is expressed at body temperature and pressure saturated (BTPS). ${ }^{3}$ I contend that this form is more useful because it allows actual calculations using real or simulated data.

Another whisper error: Siobal et al present the graphic shown in Figure 1 (their Fig. 8). In this figure, the quantity $\mathrm{V}_{\mathrm{D} \text {-alv }}$ is represented as the "shaded areas" between the volume curve and the $\mathrm{CO}_{2}$ axis. Although the vertical axis is labeled simply $\mathrm{CO} 2$, there are horizontal lines labeled $\mathrm{P}_{\mathrm{aCO}}$, $\mathrm{P}_{\mathrm{ACO}_{2}}$, et cetera, implying that the unit of measurement for the vertical axis is $\mathrm{mm} \mathrm{Hg}$. The reference is again the paper by Tusman et al. ${ }^{2}$ Out of curiosity, I looked up that paper and found a very similar graphic (Fig. 2). Note that in Figure 2 the volume axis is labeled in units of $\mathrm{mL}$, and the $\mathrm{CO}_{2}$ axis is labeled in units of $\mathrm{mm} \mathrm{Hg}$. This is ok for graph B, because all the points on the graph are either volumes or pressures. But it is not ok for graph $\mathrm{A}$. As with the first equation I mentioned, labeling the $\mathrm{CO}_{2}$ axis in units of pressure is incorrect, based on a simple dimensional analysis. The areas indicated are supposed to be volumes, but the units of those areas would be $\mathrm{mL} \times \mathrm{mm} \mathrm{Hg}$. The problem is that this figure got corrupted when it was "whispered" from its original source.

In that source, Fowler ${ }^{4}$ showed the vertical axis as $\mathrm{CO}_{2}$ concentration expressed as a fraction. Fletcher et al, ${ }^{5}$ who were referenced by Tusman et al, ${ }^{2}$ seem to have written the original article describing volumetric $\mathrm{CO}_{2}$ monitoring. They showed several graphs of volume versus fraction of $\mathrm{CO}_{2}$. Area in units of a fraction times volume yields the units of volume, as required. Tusman et al even state explicitly "The advantage of using fractions of carbon dioxide compared with partial pressure is that each area represents a volume of carbon dioxide, real or theoretical."'2

You may think the above issues are trivial matters, not worth mentioning. If you are a clinician whose main interest is basic concepts, perhaps you would be right. But if you were a researcher trying to analyze raw data, an educator trying to make a simulation with a spreadsheet, or an engineer trying to design software for a monitor, these errors could be quite confusing if you were new to the subject. 


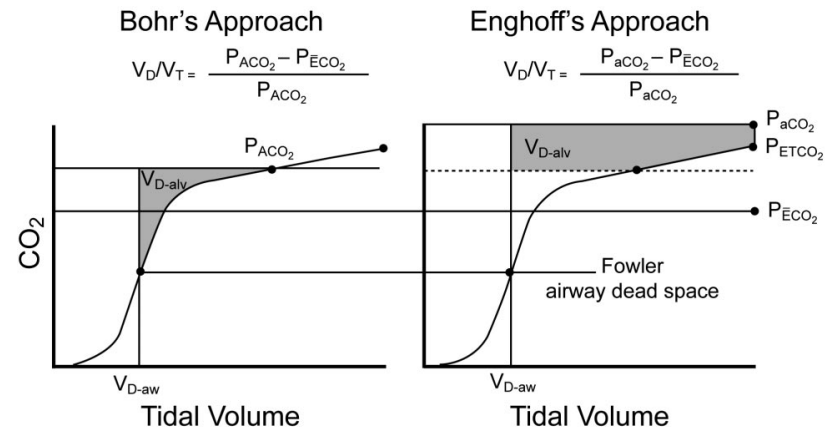

Fig. 1. Figure 8 from Siobal et al. ${ }^{1}$

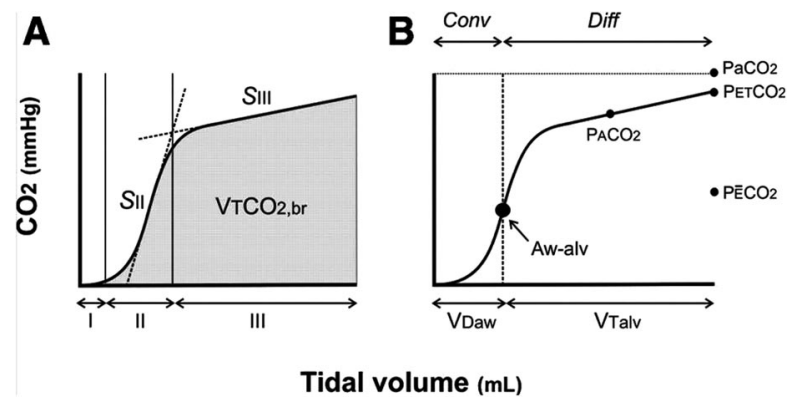

Fig. 2. Figure 2 from Tusman et al. ${ }^{2}$

Finally, I will mention a small logical inconsistency that appears throughout the literature regarding mean exhaled fraction of $\mathrm{CO}_{2}$. The term "fraction of carbon dioxide in mixed expired gas," symbolized as $\mathrm{F}_{\overline{\mathrm{ECO}}}{ }_{2}$ is attributed by Fletcher et $\mathrm{al}^{5}$ to Bohr. ${ }^{6}$ In that symbol the bar above the $\mathrm{E}$ indicates that it is a mean value. Indeed, the procedure for calculating the fraction of mixed expired gas was, historically, to collect several minutes of exhaled breaths in a large "Douglas bag" and measure the fraction of gas in the bag. Mathematically this gives the mean fraction per breath, and is analogous to measuring a minute's worth of exhalations and dividing the minute volume by the frequency to get the mean tidal volume. If you agree with this line of reasoning, then the symbol should be $\overline{\mathrm{F}}_{\mathrm{ECO}_{2}}$ or $\overline{\mathrm{P}}_{\mathrm{ECO}_{2}}$ This is admittedly a minor point, but I think it illustrates a general tendency among authors to simply pass on what previous authors have said (or what they think they said) without question.

In summary, an easy way to check mathematical expressions in manuscripts is to perform simple dimensional analyses. If the units are not the same, the equation is wrong.

\section{Robert L Chatburn MHHS RRT-NPS \\ FAARC}

Respiratory Institute

Department of Medicine

Lerner College of Medicine

Case Western Reserve University

Cleveland, Ohio

Mr Chatburn has disclosed relationships with Dräger, Hamilton, CareFusion, Covidien, ResMed, Philips, IngMar, Radiometer America, Teleflex, Strategic Dynamics, Breathe Technologies, and the Alpha-1 Antitrypsin Foundation.

\section{REFERENCES}

1. Siobal MS, Ong H, Valdes J, Tang J. Calculation of physiologic dead space: comparison of ventilator volumetric capnography to measurements by metabolic analyzer and volumetric $\mathrm{CO}_{2}$ monitor. Respir Care 2013;58(7):1143-1151.

2. Tusman G, Sipmann FS, Bohm SH. Rationale of dead space measurement by volumetric capnography. Anesth Analg 2012; 114(4):866-874

3. Cherniac RM, Cherniac L, Naimark A. Respiration in health and disease, 2nd edition. Philadelphia: WB Saunders; 1972:93.

4. Fowler WS. Lung function studies; the respiratory dead space. Am J Physiol 1948; 154(3):405-416.

5. Fletcher R, Jonson B, Cumming G, Brew J. The concept of deadspace with special ref- erence to the single breath test for carbon dioxide. Br J Anaesth 1981;53(1):77-88.

6. Bohr C. Ueber die Lungenatmung. Skand Arch Physiol 1891;2:236-268.

DOI: $10.4187 /$ respcare.02805

\section{The Whisper Game—Reply}

In reply:

We thank Mr Chatburn for reading our paper with such meticulous and extensive attention to detail as to find and point out what seem to be inconsequential mistakes. These oversights were not unintentional distortions or corrupted information, but perhaps just minor errors overlooked during the review and editing process.

Chatburn is correct in that the equation on page 1149 and in Figure 7:

$$
\mathrm{P}_{\mathrm{aCO}_{2}}=\dot{\mathrm{V}}_{\mathrm{CO}_{2}} / \dot{\mathrm{V}}_{\mathrm{A}}
$$

should have been written as a proportional relationship using the "proportional to" symbol $(\propto)$, as stated in the sentence that followed:

If $\dot{\mathrm{V}}_{\mathrm{CO}_{2}}$ increases without a proportional rise in $\dot{\mathrm{V}}_{\mathrm{A}}, \mathrm{CO}_{2}$ production exceeds $\mathrm{CO}_{2}$ excretion and $\mathrm{P}_{\mathrm{aCO}}$ increases.

It was never our intension for readers to apply this equation into clinical practice, but simply to express and illustrate the concept of the proportional relationship between $\mathrm{P}_{\mathrm{aCO}}, \mathrm{CO}_{2}$ production, and alveolar ventilation.

The precise units in a figure or the position of a dot or a bar above a character are minor if not trivial details that most people interested in learning and understanding basic concepts would normally ignore. Chatburn's approach to these inaccuracies from the perspective of a research scientist or engineer in the process of analyzing, simulating, and understanding precise data calculations are valid points for all authors, reviewers, and editors to consider.

We thank Mr Chatburn for his compulsion for accuracy and obsession to detail in pointing out these slight but important transgressions.

Mark S Siobal RRT FAARC Respiratory Care Services San Francisco General Hospital San Francisco, California

DOI: $10.4187 /$ respcare.02874 